\title{
Practical waste rock dump and stockpile management in high rainfall and seismic regions of Papua New Guinea
}

\author{
N Bar Gecko Geotechnics Pty Ltd, Australia \\ J Semi Ok Tedi Mining Limited, Papua New Guinea \\ M Koek Ok Tedi Mining Limited, Papua New Guinea \\ G Owusu-Bempah Harmony Gold Mining Company Limited, Papua New Guinea \\ A Day Harmony Gold Mining Company Limited, Papua New Guinea \\ S Nicoll Newcrest Mining Limited, Papua New Guinea \\ J Bu Newcrest Mining Limited, Papua New Guinea
}

\begin{abstract}
Papua New Guinea (PNG) is host to several topographically, geologically and climatically different environments. The central and western provinces of the mainland ('the highlands') are topographically elevated between 1,000 and 4,000 m above sea level. The terrain is very rugged and the climate is cool all year round. This region is hosted by uplifted sea floor sedimentary rocks, some of which have been metamorphosed. There is no wet or monsoon season. Rather, rainfall occurs quite steadily all year round. Annual rainfall can easily exceed $10,000 \mathrm{~mm}$ in some areas and low magnitude earthquakes are frequently experienced. The smaller outer islands are topographically flatter, seismically active and receive in the order of $5,000 \mathrm{~mm}$ annual rainfall. Rainfall usually occurs in the form of high intensity thunderstorms. The climate is very hot and humid. These islands often comprise a combination of volcanics and some sedimentary rocks.

Mining is a major industry in PNG and very large open pits have been constructed with excavated slope heights ranging from 300 to 1,000 m. Open pit mine slopes are designed with a serviceable life of no more than 10 to 20 years. As such, predicted and well-managed failures or landslides are usually considered acceptable. Waste rock and low-grade ore are often placed in constructed rockfill dumps and stockpiles which range in heights from 50 to over $300 \mathrm{~m}$. High rockfill slope heights developed on often steep foundations, coupled with the erosive and pore pressure effects of rainfall and seismicity can create significant landslide hazards. This paper presents the cumulative efforts of practitioners managing risks associated with rockfill dumps and stockpiles in PNG.
\end{abstract}

Keywords: rockfill, colluvium, waste rock dumps, stockpiles, slope stability

\section{$1 \quad$ Introduction}

Papua New Guinea (PNG) is host to diverse topographic, geological and climatic settings. The central and western provinces of the mainland ('the highlands') are topographically elevated between 1,000 and 4,000 $\mathrm{m}$ above sea level. This region is hosted by uplifted sea floor sedimentary rocks with some intrusions and metamorphic rocks. There is no wet or monsoon season. Rather, rainfall occurs steadily all year round. Annual rainfall can easily exceed $10,000 \mathrm{~mm}$ and low magnitude earthquakes are frequently experienced. High magnitude earthquakes occur much less frequently, although the latest was a devastating magnitude 7.5 earthquake that occurred in Hela Province on 26 February 2018.

The smaller outer islands are topographically flatter, although locally high peaks of over $500 \mathrm{~m}$ above sea level are still quite common. The region is seismically active and receives in the order of 5,000 mm annual rainfall. However, rainfall usually occurs in the form of high intensity thunderstorms. The climate is very hot 
and humid and these islands comprise a combination of volcanics and some sedimentary rocks. Much of the waste rock mined is subject to rapid weathering upon exposure to the atmosphere.

Mining is a major industry in PNG and large open pit mines have been constructed with excavated slope heights ranging from 300 to $1,000 \mathrm{~m}$.

Open pit mine slopes are designed with a serviceable life of no more than 10 to 20 years (Bar et al. 2014). As such, predicted and well-managed slope failures or landslides are usually considered acceptable.

Waste rock and low-grade ore are often placed in rockfill dumps and stockpiles which range in heights from 50 to over $300 \mathrm{~m}$ as shown in Figure 1. Most dumps and stockpiles have a similar serviceable life to mine slopes; however, some are even designed to be 'erodible' or 'failing' dumps whereby the rate of erosion or failures is effectively equal to the dumping advance rate.

Rugged foundation terrain, poor foundation material, high rainfall, and seismic activity facilitate high deformations and frequent landslide activity on rockfill dumps and stockpiles in Papua New Guinea.

This paper uses case studies from various mines in PNG to demonstrate the complexities and challenges of rockfill dump and stockpile construction and management.

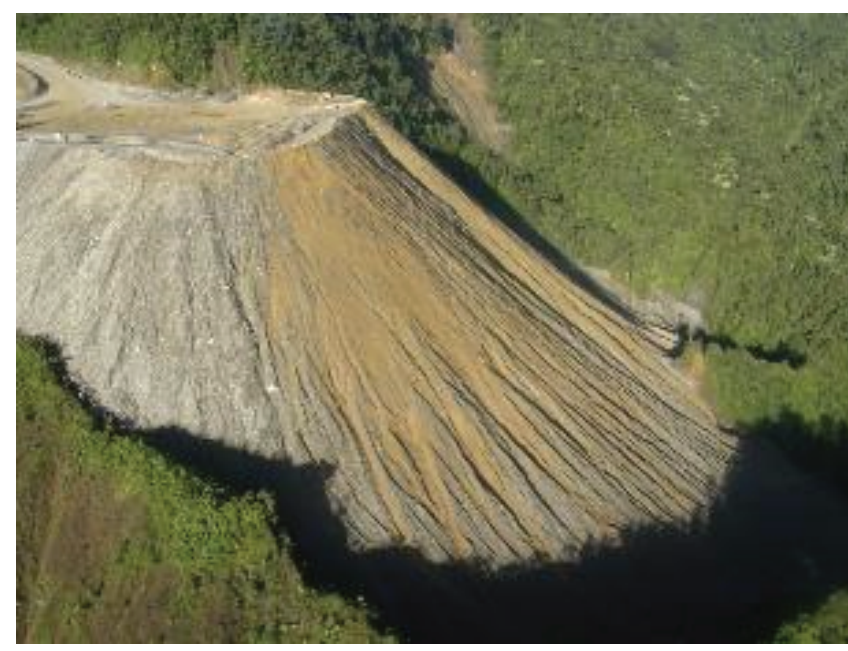

(a)

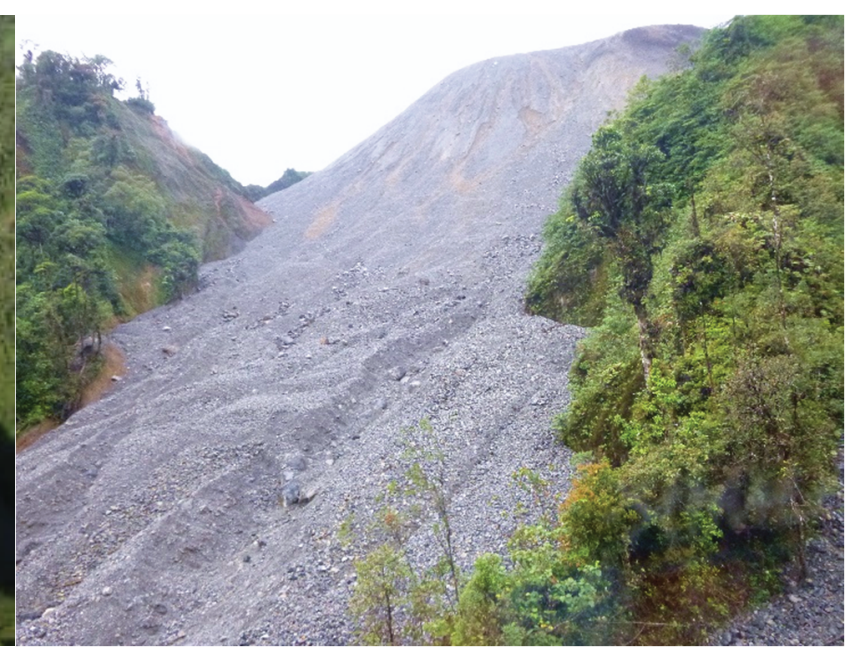

(b)

Figure 1 Vancouver rockfill dump (Ok Tedi copper-gold mine): top-down construction extending outward with a $300 \mathrm{~m}$ high tip-head. (a) Aerial view; (b) View near dump base

\subsection{Vancouver rockfill dump, Ok Tedi copper-gold mine}

Vancouver rockfill dump is the largest dump constructed at Ok Tedi copper-gold mine (Figure 1). The dump site was selected within a large, steep gully that both deepens and widens downslope (i.e. as the dump advances outward, the dump height increases). Average annual rainfall at the dump site is approximately $10,000 \mathrm{~mm}$.

The dump foundation is a combination of colluvium, debris from historic landslide events, and riverine sediments overlaying fresh limestone bedrock. Due to the rugged topography, no form of foundation preparation was economically feasible.

When originally considered as a feasible dumping location, Vancouver rockfill dump was envisaged to be an 'erodible' dump (Fisher et al. 2003) with quite limited capacity associated with frequent instabilities and remediation work.

Material placed in the dump was mostly coarse, fresh limestone rock. 
Several crest or tip-head instabilities have occurred since construction commenced in 2011, causing troublesome but manageable delays to operations. On average, it could be said that signs of instability are detected on a weekly basis.

However, the rockfill dump in its entirety has been constructed and remains stable. The tip-head crest has since advanced outward from the in situ starting point by over $270 \mathrm{~m}$, averaging about $50 \mathrm{~m}$ per year. The tip-head height ranges from $150 \mathrm{~m}$ at the sides to $385 \mathrm{~m}$ in the middle. The dump currently contains almost two million cubic metres of rockfill.

An additional risk associated with the dump is its proximity to the historic Vancouver landslide (Read \& Maconochie 1992).

Near-real time monitoring, twice-daily inspections by geotechnical engineers and remote controlled bulldozers are just some of the control measures used to manage instability risks at Vancouver rockfill dump.

\subsection{Kapit North stockpile, Lihir gold mine}

Kapit North stockpile is not the largest stockpile at Lihir gold mine, but it is one that presents a unique risk (Figure 2) including impact to road networks and mine infrastructure at the base of the stockpile.

It is founded on a layer of weak colluvium (5-20+ $\mathrm{m}$ thick) and the foundation topography increases in steepness from $5^{\circ}$ at the base to about $30^{\circ}$ at the top of the designed stockpile.

The stockpile contains low-grade ore that is periodically reclaimed (i.e. loading and unloading). It has been under construction for over a decade and will remain in use for several years to come.

Material placed in the stockpile is a combination of relatively weak to medium strong rock and highly weathered to decomposed rock. These materials are often also are susceptible to further deterioration from weathering processes.

Stockpile construction has involved the removal of topsoil for foundation preparation; however, the underlying weak colluvium remains. Freshwater under-drains have also been constructed at major creeks to reduce water ingress into the stockpile and reduce the likelihood of pore pressure build-up.

No major instabilities have occurred at the stockpile. Monitoring instrumentation indicates the dump is both settling and creeping seaward.

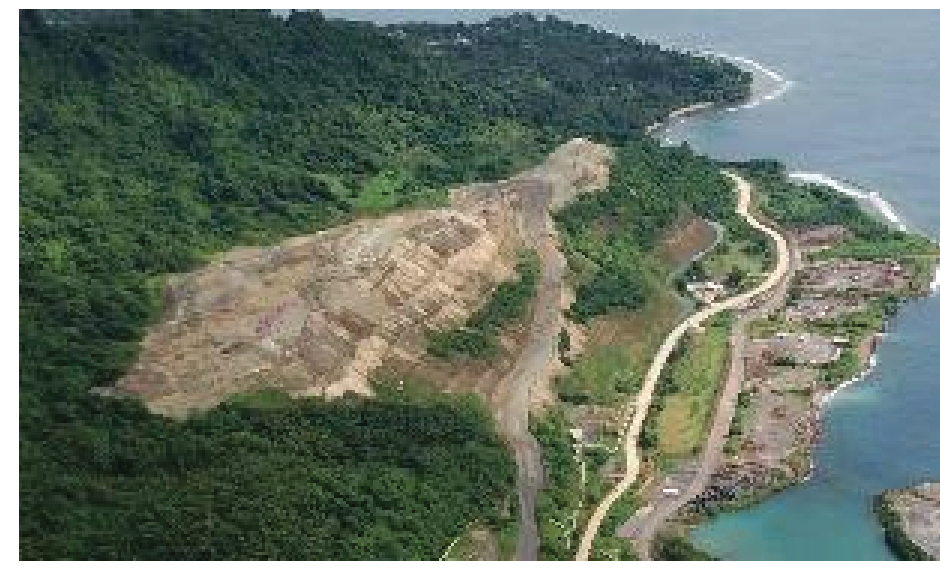

(a)

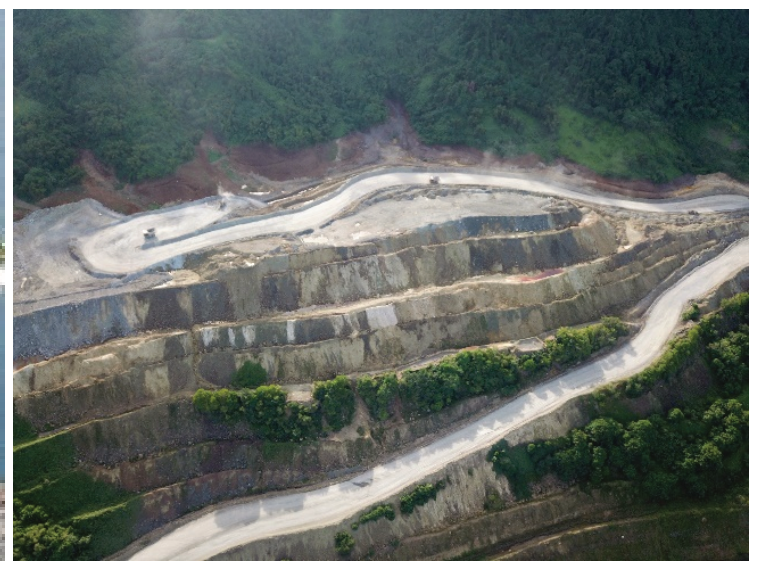

(b)

Figure 2 Kapit North stockpile (Lihir Island): bottom-up construction. Current height: $110 \mathrm{~m}$; final height: $190 \mathrm{~m}$. (a) Aerial view; (b) Upper levels and foundation preparation for next lift 


\subsection{Neikywe waste rock dump, Hidden Valley gold-silver mine}

Neikywe waste rock dump is one of the main dumps of Hidden Valley gold-silver mine, designed to accommodate a large volume of waste rock during the life-of-mine. Waste dump allocation at Hidden Valley is challenging due to the topographically elevated setting and limited practical area for a dump footprint. The selection of the Neikywe dump location was strategic in terms of cost and engineering for the Hidden Valley operation to ensure ongoing mining, effective management of waste rock and optimise volume of waste from the pits. The dump is located about $460 \mathrm{~m}$ north of the main Hidden Valley and Kaveroi pits.

Hidden Valley receives approximately $3,000 \mathrm{~mm}$ of annual rainfall and Neikywe waste rock dump is located at an elevation between 1,700 and 2,800 $\mathrm{m}$ above sea level in the forested terrain of the mine (Figure 3). The terrain is characterised by valleys of steep dipping elevation profiles and active creeks. Surface water management is key to maintaining the stability of the dump. The dump lifts are raised using paddock dumping (i.e. are not end-tipped). The material is then dozed and mechanically compacted through repetitive haulage cycles from Caterpillar 785 dump trucks to achieve a rockfill density in the order of $2,200 \mathrm{~kg} / \mathrm{m}^{3}$ to improve stability.

The Neikywe dump is being constructed by bottom-up approach; however, access to the dump toe was first constructed using a (top-down) ramp on shallow-to-steep foundation profile angle ranging from $15^{\circ}$ to about $40^{\circ}$ between 2,500 and 2,126 $\mathrm{m}$ above sea level. The early stage top-down construction approach enabled access to the dump toe to develop a $45 \mathrm{~m}$ high engineered buttress and underdrain infrastructure. The dump is confined in the valley and founded on a 2 to $30 \mathrm{~m}$ thick colluvium deposit, which overlies weathered granodiorite.

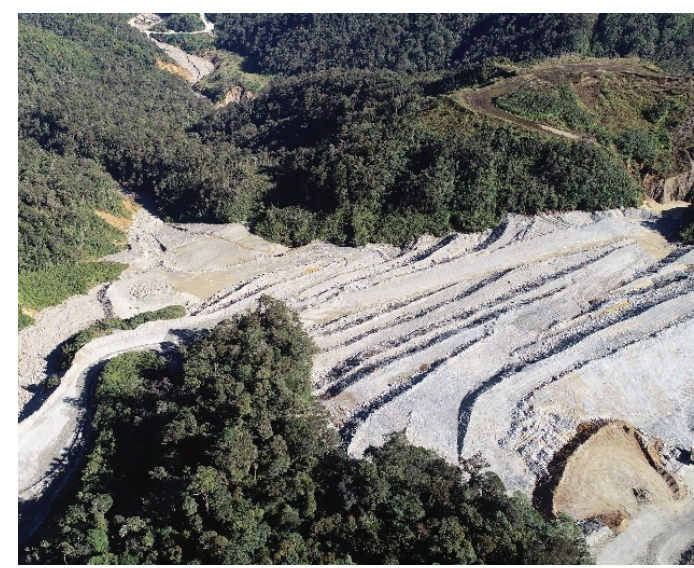

(a)

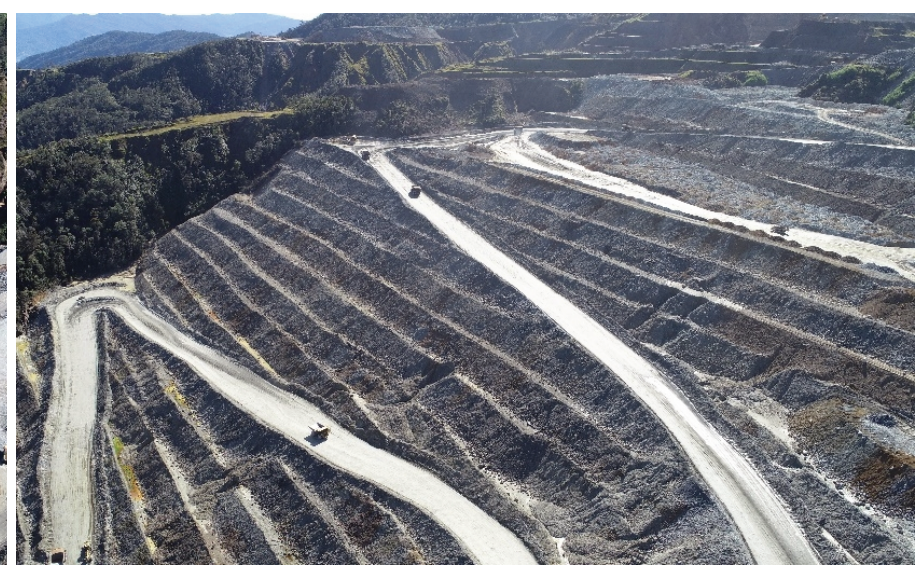

(b)

Figure 3 Neikywe waste rock dump (Hidden Valley gold-silver mine); bottom-up construction. (a) Dump toe locked into natural valley from historic creek; (b) Upper levels (10 m high lifts)

Waste rock for the dump is sourced from the Hidden Valley and Kaveroi open pits and comprises weathered and altered granodiorite with relatively high clay content and oxidised metasediments including weak and friable schists. Potentially acid forming rocks are encapsulated by non-acid forming layers to meet environmental requirements.

Construction management generally involves placing material in a sequence to create free-draining beds that prevent pore pressure building and improve stability. Vibrating wire piezometers are used to monitor water levels and pore pressure during successive dump lifts.

Deformations are monitored with survey prisms and indicate in the order of $100 \mathrm{~mm}$ of creep and settlement are observed per year.

Surface water drainage management and maintenance are key controls for managing short-term stability and the serviceability of haulage ramps. 


\subsection{Moscow erodible dump, Ok Tedi copper-gold mine}

Moscow erodible dump is shown in Figure 4 alongside Harvey Creek rockfill dump. For context, the Harvey Creek rockfill dump tip-head is approaching $300 \mathrm{~m}$ at the highest point, and the flow path continuously generated from Moscow erodible dump is in excess of $600 \mathrm{~m}$.

Under normal operating conditions, the Moscow erodible dump does not advance outward. Rather, material is dumped up to $30 \mathrm{~m}$ away from the tip-head crest and is then pushed over the crest using remote controlled bulldozers as shown in Figure 4. This material essentially flows down the slope into Harvey Creek with effectively no accumulation of the dump face, or advance of the tip-head.

The foundation is a very steep cliff $\left(\geq 60^{\circ}\right)$ in some parts of the dumping location and gradually reducing to about $30^{\circ}$ near the base where it meets Harvey Creek. The foundation originally had a similar composition to that of Vancouver rockfill dump; however, with decades of dumping and erosion, it is likely that most of the foundation, particularly in the upper parts of Moscow erodible dump are now fresh bedrock, typically limestone and siltstone.

Rainfall at Harvey Creek and Moscow dumps is on average 10\% more than at Vancouver rockfill dump (Bar et al. 2014). The consistently high rainfall persuades material to erode from the tip-head. However, in some instances, a high amount of fines, and even clay content in the rockfill can locally 'hold together' and permit the tip-head to advance outward several metres. If unmonitored or unknown, this can pose a significant threat to equipment and personnel on the tip-head. Such instances result in rapid-failure, usually during or after rainfall events.

Control measures used to minimise risk are similar to those at Vancouver rockfill dump.
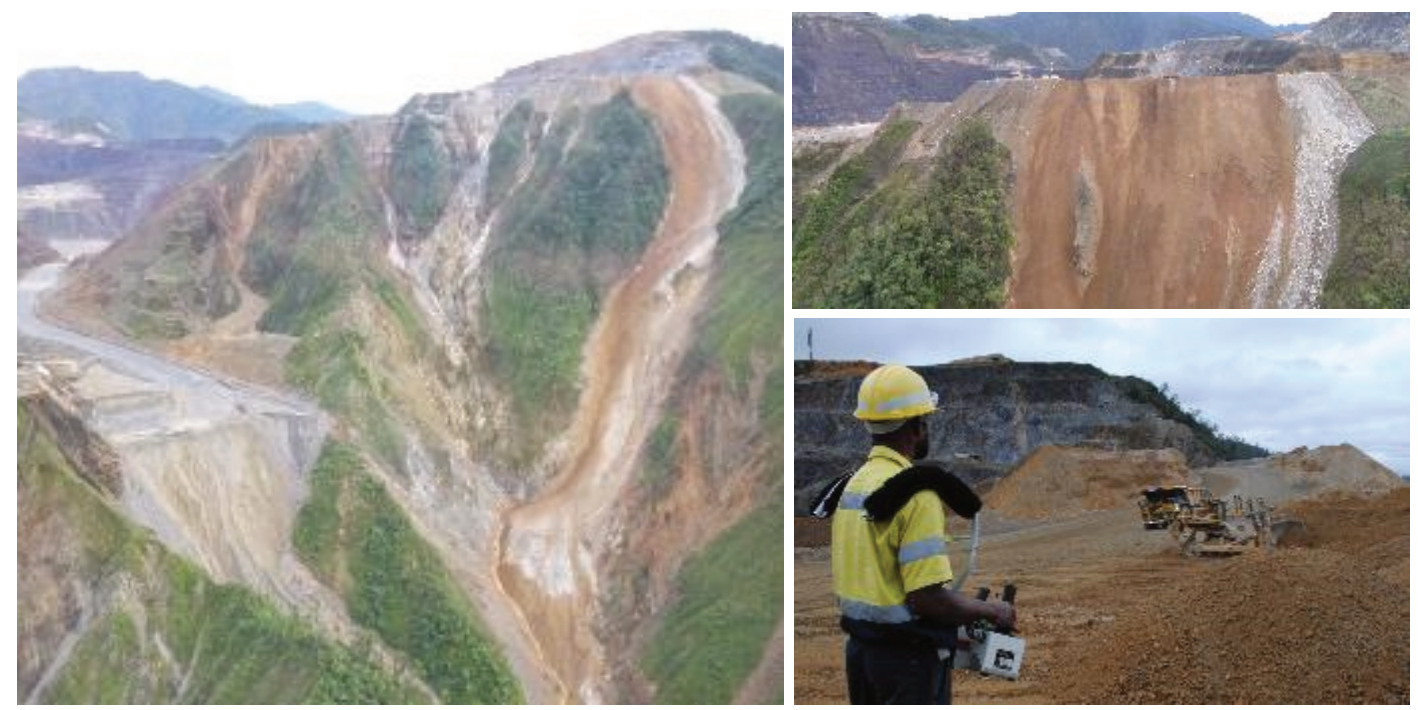

Figure 4 Moscow erodible dump (Ok Tedi copper-gold mine); clockwise from left: Harvey Creek rockfill dump (lower-left) and Moscow erodible dump (upper-right); Moscow tip-head; example of standard operational procedures: remote control bulldozer operator at Moscow erodible dump tip-head pushing material from up to $30 \mathrm{~m}$ behind the crest

\section{WSRHC system (waste dump and stockpile stability rating and hazard classification)}

Rockfill dumps and stockpiles can be categorised using the WSRHC system initially developed by Hawley (2000) and recently updated by Hawley \& Cunning (2017).

The WSRHC system is based on a collation of data obtained from surveys of various waste dumps and stockpiles and aims to provide guidance on the suggested level of effort required for site investigations and characterisation, analysis and design, construction and operational risk management. The WSRHC system 
utilises a combination of an engineering geology index (EGI) and a design and performance index (DPI) to derive a waste dump and stockpile stability rating (WSR). EGI is determined by considering:

- Regional setting: seismicity and precipitation.

- Foundation conditions: foundation slope and shape, overburden type and thickness, undrained failure potential, foundation liquefaction potential, bedrock and groundwater.

- Material quality: gradation, intact strength and durability, material liquefaction potential and chemical stability.

DPI is determined by considering:

- Geometry and mass: height, slope angle, volume and mass.

- Stability analysis: static and dynamic stability.

- Construction: construction method and loading rate.

- Performance: stability performance.

WSR is then obtained with the summation of EGI and DPI.

Five waste dump and stockpile hazard classes (WHC) from WHC I (very low hazard) to WHC V (very high hazard) can be assigned depending on the EGI and DPI as shown in Figure 5.

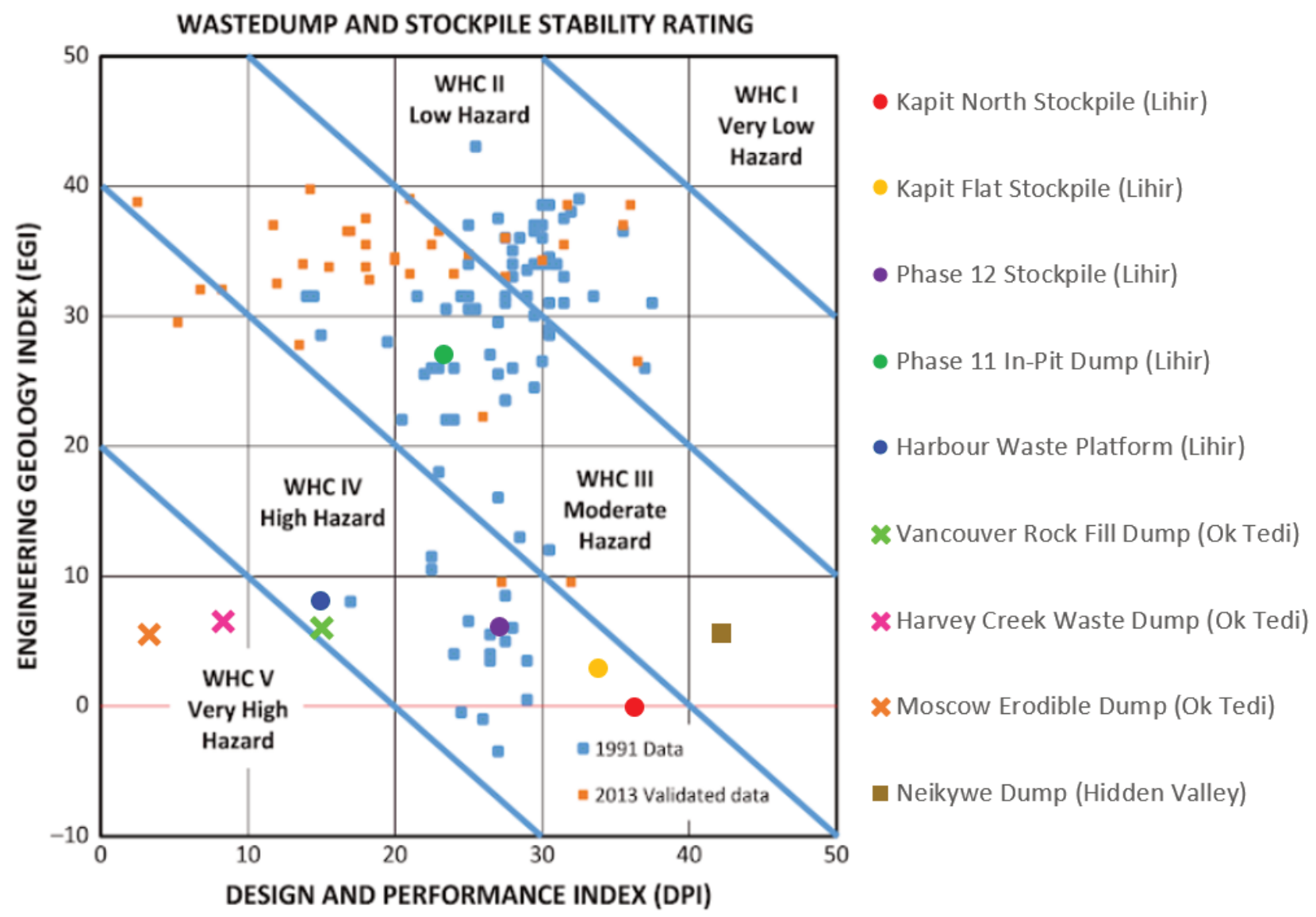

Figure 5 Waste dump and stockpile stability and hazard chart illustrating the 1991-2013 surveys by Hawley \& Cunning (2017) and the rockfill dumps \& stockpiles from various mines in Papua New Guinea 
It is evident that the rockfill dumps and stockpiles from the mines in PNG are much higher risk than those in the remainder of the 1991-2013 database by Hawley \& Cunning (2017). Key factors in the higher risk profile of rockfill dumps and stockpiles in PNG are:

- Low DPI arising from top-down construction or end-dumping into steep valleys as is the case for Vancouver, Harvey Creek and Moscow dumps. These result in WHC IV (high hazards) to WHC V (very high hazards).

- Low EGI in general due to regional setting, and in particular, an extremely low EGI for stockpiles constructed on steep and weak foundation slopes. These typically result in WHC IV (high hazards).

\section{Site investigations, analysis, design and reconciliation}

This paper focuses on the practical (operational) management of rockfill dumps and stockpiles, rather than the details of their design. However, for context, it is necessary to outline the level of rigour involved during site investigations, analysis and design of these structures, typically rated as high to very high hazards.

Furthermore, it is imperative the readers understand that once construction commences, assumptions made, or uncertainties remaining from the site investigations and the design process require validation or reconciliation with both time and as construction stages progress.

\subsection{Site investigations}

Site investigations for rockfill dumps and stockpiles in PNG are generally almost as detailed as investigations for the open pits themselves. Typically included are:

- Topographical surveys.

- Surface mapping of foundation slopes and material as well as understanding historic landslide events.

- Mapping and understanding natural waterways to enable appropriate surface water diversion.

- Geophysical surveys to understand the general types of foundation material.

- Boreholes are often dual purpose, firstly for detailed ground characterisation and understanding pre-construction groundwater, and secondly for the installation of monitoring instrumentation for understanding subsurface deformation and pore pressures before, during and after construction.

- Laboratory testing of samples.

Another fundamental aspect of the site investigations is characterising rockfill material that will be used in the dumps or stockpiles. In most cases, either blasted stocks or small existing rockfill dumps or stockpiles are available. Site investigations typically comprise:

- Rockfill characterisation including intact material strength, particle size distributions, particle shape, and porosity (Barton 2008; Barton \& Kjaernsli 1981).

- In rare instances, bulk samples are gathered for laboratory testing.

- If available, back-analysing any existing failures within rockfill material.

\subsection{Analysis and design}

The level of analysis is often dependent on a combination of the level of risk and the amount of available data. In most cases, static and pseudo-static analyses are carried out using two-dimensional (2D) limit equilibrium (LEM) or finite element methods (FEM) to understand the Factor of Safety (FS) or critical strength reduction factor (SRF) for the design. 
For complex, three-dimensional terrain and foundations, more rigorous 3D analysis is often required, particularly when 2D analyses attain lower than desirable FS/SRF (Bar \& Weekes 2017; Bar et al. 2019), as is the case in Figure 6. Again, depending on the complexity of the problem, 3D analyses could range from relatively simple limit equilibrium or finite element to more complex particle flow codes.

Tip-head stability is a material risk for mining equipment and understanding what conditions are required to trigger instability are critical for improving safe operating practices. By way of example in Figure 7, LEM and FEM are back-analyses of failure events at Vancouver rockfill dump. Such analysis results, in conjunction with monitoring results, can then be used to develop crest stand-off distances.

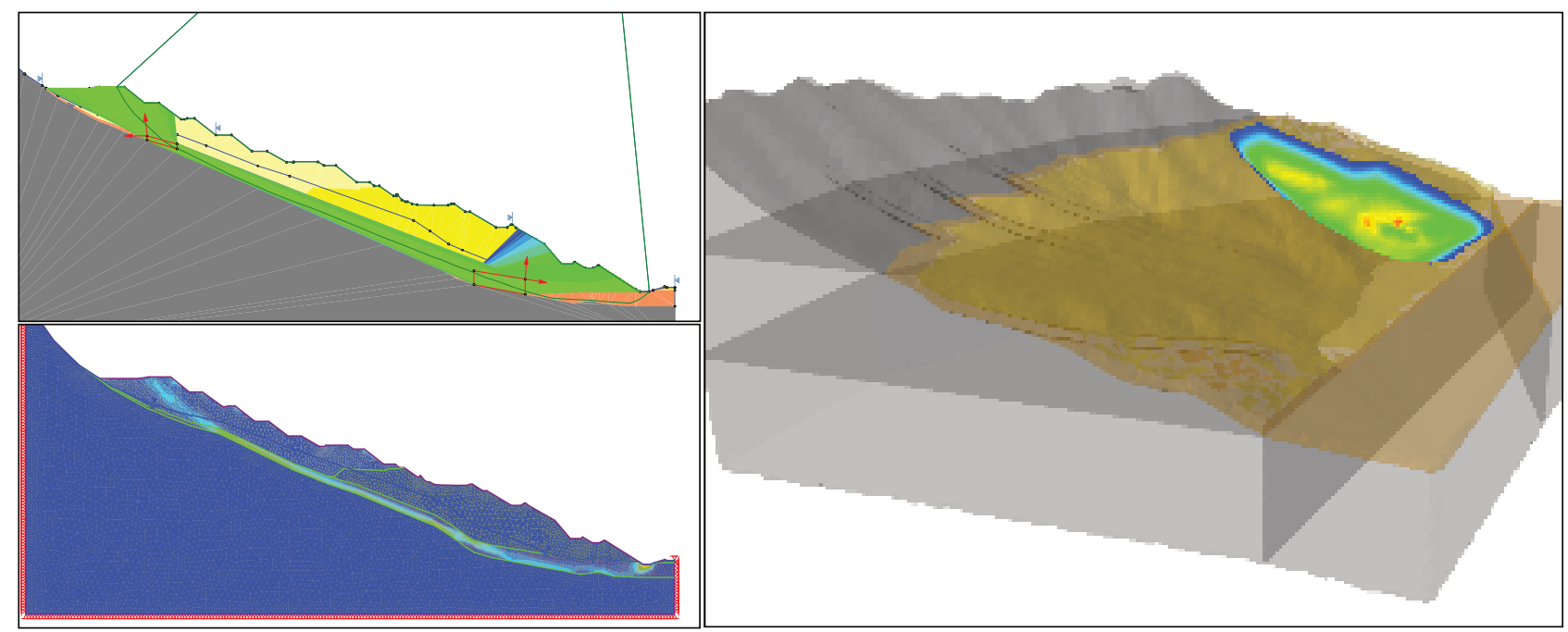

Figure 6 Examples of stability models for Kapit North stockpile design where sliding on the weak colluvium foundation $\left(c^{\prime}=10 \mathrm{kPa} ; \phi^{\prime}=30^{\circ}\right)$ was identified as the most plausible failure mechanism; however, Factors of Safety indicate stable conditions aligning with industry standard design acceptance criteria; Top-left: 2D LEM FS = 1.22 (GLE \& Spencer method of slices); Bottom-left: 2D FEM indicating maximum shear strain through colluvium with critical SRF = 1.21; Right: 3D LEM FS > 1.3 (GLE and Spencer method of columns)

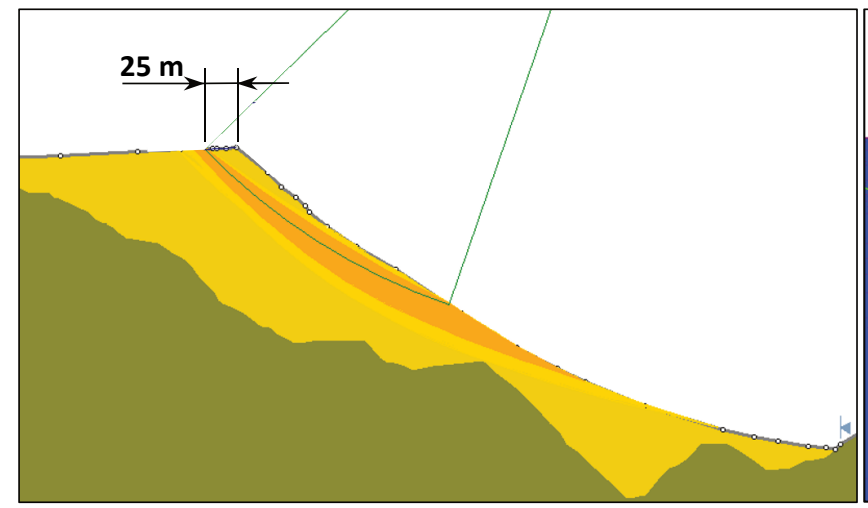

(a)

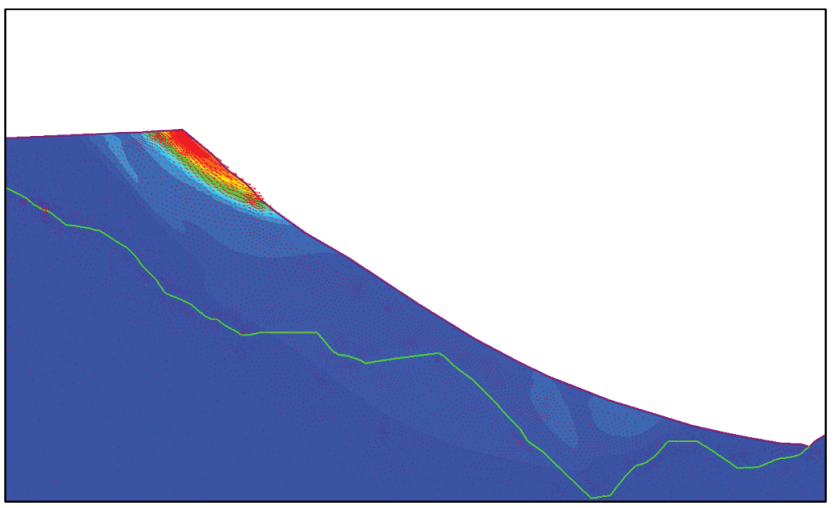

(b)

Figure 7 Examples of tip-head stability models for Vancouver rockfill dump. (a) 2D LEM back-analysis of failure induced by poor material quality comprising high fines (silts, clays and sands) content within the rockfill; (b) 2D FEM back-analysis of failure induced by crest over-steepening with deformations calibrated by monitoring results 


\subsection{Reconciliation}

Regular visual inspections of active rockfill dumps and stockpiles are critical for both identifying and managing hazards as well as for reconciling assumptions made in the design. Moreover, when failures occur, it is essential that both pre and post failure conditions are fully understood. As a result, a series of checks and measurements are carried out on each inspection, and include but are not limited to:

- Horizontal distance from the dump crest to in situ foundation (to understand advance rates for top-down construction).

- Dump crest and overall dump face angles.

- Dump crest length and curvature (usually through surveying but also qualitative - straight, convex, concave or irregular).

- Visible signs of erosion on the dump crest, face or at the base of the dump resulting in undercutting. Notes on any other signs of instability.

- Daily rainfall, cumulative rainfall (e.g. 2-5 day period) and rainfall intensity (millimetres per hour).

- Foundation material type and quality.

- Completion or otherwise of prescribed foundation preparation.

- Effectiveness of surface water drainage measures.

- Dumped material quality (both qualitatively and detailed rockfill characterisation).

- Long-term deformation and pore pressure data (although this is not usually recorded on a routine inspection).

- Regular verification that risk control measures are both in place and effective.

Depending on the level of risk and activity at a particular tip-head, inspections may be undertaken weekly or even multiple times per day as is standard practice at Ok Tedi copper-gold mine. This results in a very large volume of data that requires storage and ease-of-access. Bar et al. (2018) discuss data management challenges and initiatives that have been applied in PNG to facilitate this.

Understanding the triggers or precursors to failures, particularly at dump tip-heads, is fundamental in implementing effective construction and operational risk management strategies.

\section{$4 \quad$ Construction and operational risk management strategies}

\subsection{Top-down construction methodology}

Top-down construction is used for many rockfill dumps and stockpiles in PNG (e.g. Vancouver, Harvey Creek and Moscow in the case studies discussed earlier).

Since the tip-head heights are very large, material segregation caused by gravity occurs, typically allowing coarser material to settle at the base of the dump, and finer material to remain closer to the crest.

As mentioned previously, a higher concentration of fines near the crest, some over-steepening, and high rainfall facilitates frequent tip-head or dump crest failures.

In order to maintain continuous operability with frequent instabilities, a top-down construction dump is separated into individual tip-heads that operate almost independently. That way, if cracking, slumping or other signs of instability occur on one, the other tip-head/s can remain operational while the unstable tip-head is either remediated or is given time to settle or fail.

At Vancouver rockfill dump, for example, it has been found that if tip-heads are allowed to advance for more than seven days in a single period, instability is likely to ensue. Managing the rate of crest advance 
has been a key control in maintaining routine operability at most of the top-down construction dumps and stockpiles. On the contrary, when a crest instability has been realised at Vancouver rockfill dump, typically the remediation strategy involves cutting the dump crest down by approximately $5 \mathrm{~m}$ up to a distance of about $20 \mathrm{~m}$ from the crest (at least to the location where cracking has been identified).

Surface water management is critical for ensuring the base of the dump is not undercut and potentially causing a larger instability.

\subsection{Safety-critical control measures}

Top-down construction with very high tip-heads naturally presents a very high risk.

Operational risk management strategies centre around removing the need for personnel to work near the dump crest as illustrated in Figure 8. Haul trucks and other human-operated heavy equipment are kept a significant distance away from the crest. That means material is dumped a significant distance away from the crest and subsequently has to be pushed by a remote controlled bulldozer over the crest.

Yellow marker poles are established to provide haul truck operators a physical location to align their cabin with and tip the waste (Figure 8).

An orange cone is used to demarcate the closest location a dump supervisor or remote controlled bulldozer operator can be positioned under regular operating conditions.

In the case of Vancouver rockfill dump, yellow marker poles are installed $35 \mathrm{~m}$ from the crest of the tip-head. Based on the length of the haul trucks used, this prevents the haul trucks from working within $30 \mathrm{~m}$ of the crest.

The dump tip-head work area is constructed at a $2 \%$ upward gradient to allow surface water to freely drain away from the crest and towards concreted drains to minimise infiltration.

For high risk rockfill dumps such as Vancouver rockfill dump, the quality of material dumped is also monitored. Poor quality material with high fines and clay content is diverted and sent to other, lower risk dump areas.

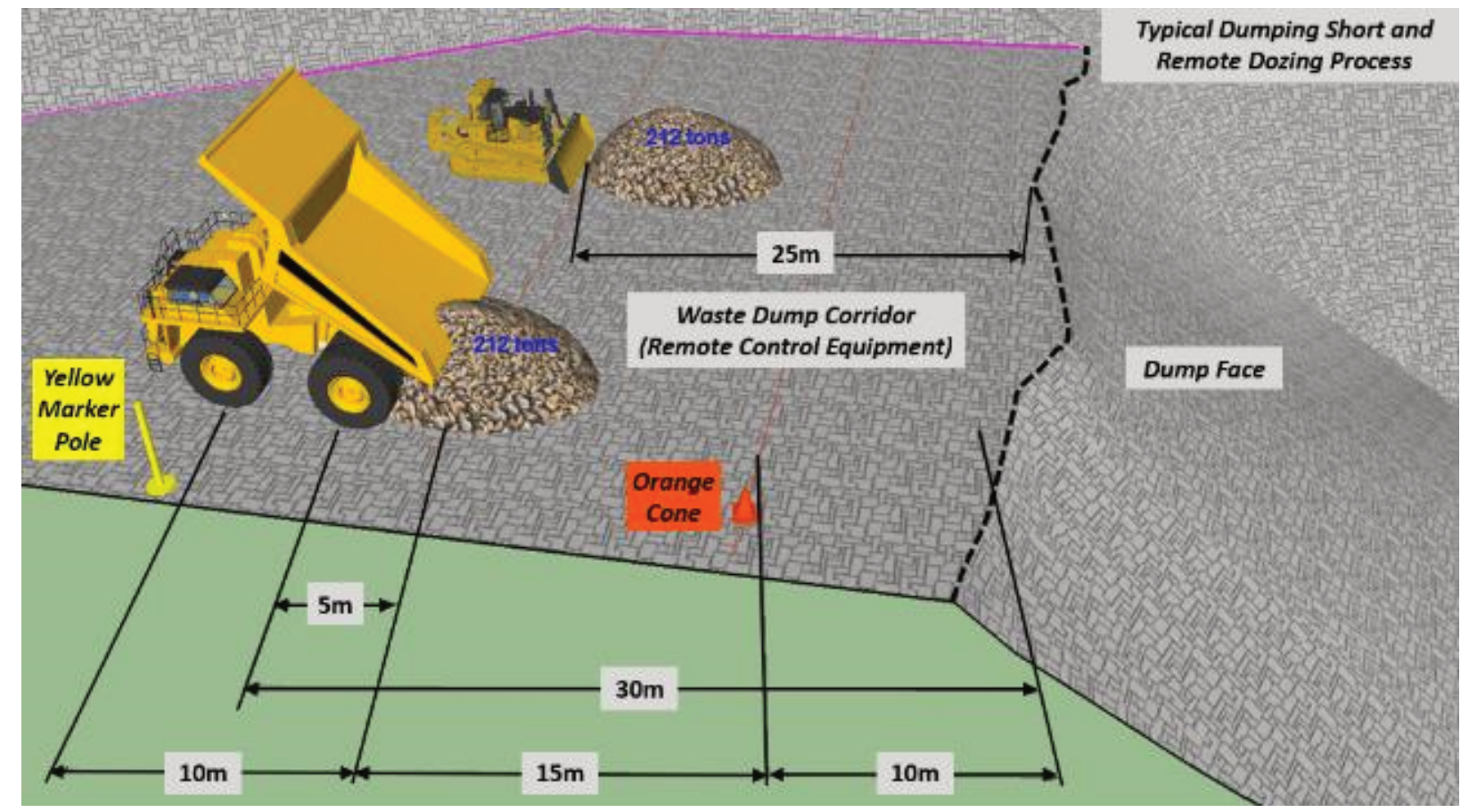

Figure 8 Schematic illustrating typical process for dumping short and remote dozing to prevent personnel near tip-head 
Since most instabilities are triggered by rainfall, detailed trigger action response plans (TARP) are in place to manage, and where necessary cease, dumping operations at each individual rockfill dump.

Deformation monitoring instrumentation and groundwater monitoring are often also primary control measures for managing safety risks on the rockfill dumps.

This process is endorsed by the Mineral Resource Authority of Papua New Guinea.

\subsection{Monitoring}

A diversity of slope and groundwater monitoring instruments and systems exists; ranging from rudimentary, manual wire or tape extensometers, to highly sophisticated electronic equipment (Baczynski \& Bar 2017).

Rockfill dumps and stockpiles in PNG are typically monitored with an array of instrumentation to better understand ground behaviour with the aim of reducing risk to people, equipment and the environment.

Surface deformation monitoring instrumentation on dumps and stockpiles can comprise an array of:

- Rudimentary manual wire or tape extensometers that are interrogated on each visual inspection.

- Wireline extensometers with audiovisual alarms, data loggers and telemetry systems (Slide Minder) as shown in Figure 9.

- Survey prisms automatically surveyed using robotic total stations.

- Global positioning systems (GPS).

- Interferometric synthetic aperture radar (InSAR or satellite monitoring).

Subsurface monitoring typically involves the use of inclinometers, or a more automated substitute such as shape-accel arrays, time-domain reflectometers or recently developed SMART markers with tilt sensors.

Pore pressures in the dump material or its foundation can be monitored using vibrating wire piezometers.

Both subsurface deformation and groundwater monitoring instrumentation can provide very early warning of a potential problem compared with surface monitoring.

A combination of surface and subsurface monitoring is advisable to monitor for both short-term and long-term instability risks.

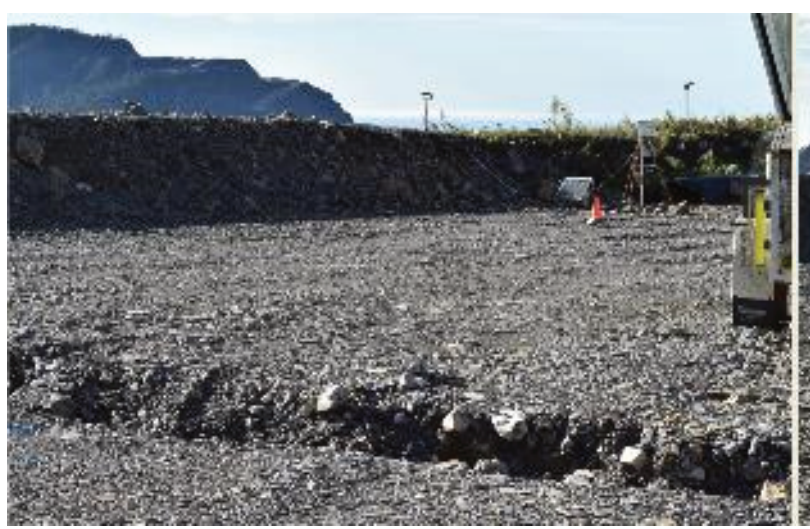

(a)

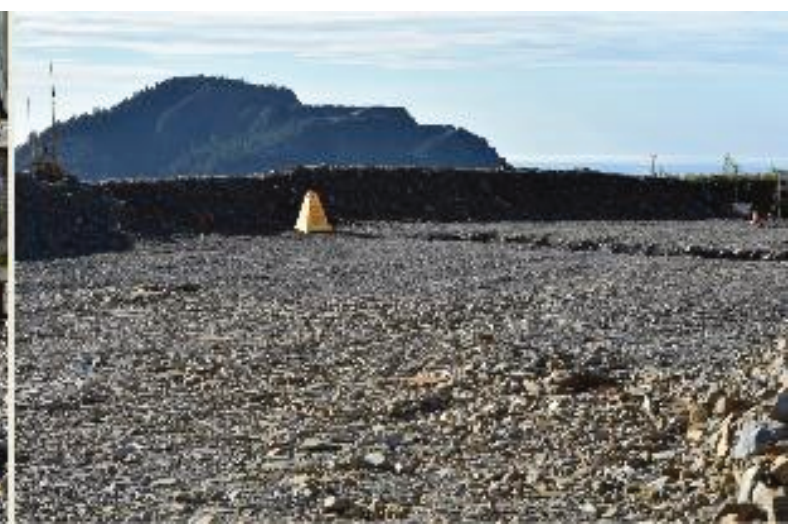

(b)

Figure 9 Monitoring the extension of a tension crack using: (a) Slide Minder and survey prisms; (b) GPS

\section{Conclusion}

Topographic, geologic and climatic conditions including high rainfall and seismicity in PNG set the scene for rockfill dump and stockpile construction in areas with a very low EGI, and therefore, moderate to very high 
hazard ratings using the WSRHC system. The DPI varies substantially depending on the construction practices used. Top-down construction onto steep foundations results in very high hazard ratings that need effective control measures, key aspects of which have been described in this paper.

Irrespective of construction methods, the priority for rockfill dump and stockpile management in a high rainfall and seismically active region is the safety of personnel operating on them, and the persons or communities that may be affected should a major instability occur.

State-of-the-art surface and subsurface deformation monitoring and groundwater monitoring instrumentation has been utilised in all cases for providing early warning for emerging hazards. Detailed TARPs are used to ensure key stakeholders are promptly informed and know how to respond to a potential threat.

Regular inspections (twice-daily in many cases) by geotechnical engineers, geotechnical hazard awareness training and highly experienced operators permit hazards to be identified early, and in many cases, be controlled or remediated before an instability occurs. This usually reduces delays to production.

Effectively managing surface water drainage is critical for all of the cases. For top-down construction, managing the challenge of operational requirements and dump crest advance rates is often another critical aspect for reducing the likelihood of instability (and further delays to production).

\section{Acknowledgement}

The authors acknowledge support from their colleagues at their respective mining operations; in particular: Marisa Torombe, Priscilla Ipul, Paul Kuira, Chris Alickson, Sinaka Rea, Geyson Akore, Daniel Pohonu, Sonnia Asamole, Gideon Tongri, Micheal Maima, Roberto Giglio, Juanito Asuro, Kaipale Pano, Simon Thomas, Robert Parker and Norbert Baczynski.

The authors also thank Rocscience Inc. for their support with using their limit equilibrium (Slide and Slide3) and finite element (RS2) analysis software.

\section{References}

Baczynski, NRP \& Bar, N 2017, 'Landslide monitoring and management challenge in remote Papua New Guinea', Proceedings of the 4th World Landslide Forum, Springer, Cham, pp. 343-354.

Bar, N, Kuira, P \& Semi, J 2014, 'Managing risk associated with erosion-driven slope instabilities with ground support \& surface water management in a high rainfall environment at Ok Tedi Copper-Gold Mine', Proceedings of Mastering Complex Projects Conference 2014, Engineers Australia, Barton, pp. 191-202.

Bar, N, Reynolds, M, Nicoll, S \& Bran, D 2018, 'Geotechnical data management and visualization systems: meeting the data challenge of the 21st century and maximizing value for open pit mines', in V Litvinenko (ed.), Proceedings of the 2018 European Rock Mechanics Symposium: Eurock 2018, CRC Press, Boca Raton.

Bar, N \& Weekes, G 2017, 'Directional shear strength models in 2D and 3D limit equilibrium analyses to assess the stability of anisotropic rock slopes in the Pilbara Region of Western Australia', Australian Geomechanics Journal, vol. 52, no. 4, pp. 91-104.

Bar, N, Yacoub, TE \& McQuillan A 2019, 'Analysis of a large open pit mine in Western Australia using finite element and limit equilibrium methods', Proceedings of the 53rd US Rock Mechanics/Geomechanics Symposium, American Rock Mechanics Association, Alexandria, $8 \mathrm{p}$.

Barton, NR 2008, 'Shear strength of rockfill, interfaces and rock joints, and their points of contact in rock dump design', in AB Fourie (ed.), Proceedings of The First International Seminar on the Management of Rock Dumps, Stockpiles and Heap Leach Pads, Australian Centre for Geomechanics, Perth, pp. 3-18.

Barton, NR \& Kjaernsli, B 1981, 'Shear strength of rockfill', Journal of the Geotechnical Engineering Division: Proceedings of the American Society of Civil Engineers, vol. 107-GT7, pp. 873-891.

Fisher, M, Davies, M, Anderson, WS \& Savigny, KW 2003, 'Stewarding mine dump mass movements by regional landslide analogy', Proceedings of the 3rd Canadian Conference on Geotechniques and Natural Hazards, Canadian Geotechnical Society, Edmonton.

Hawley, M 2000, 'Site selection, characterization, and assessment', Proceedings of Slope Stability in Surface Mining, Society for Mining, Metallurgy \& Exploration, Englewood, pp. 267-274.

Hawley, M \& Cunning, J 2017, Guidelines for Mine Waste Dump and Stockpile Design, CSIRO Publishing, Clayton, 370 p.

Read, JRL \& Maconochie, AP 1992, 'The Vancouver Ridge landslide, Ok Tedi Mine, Papua New Guinea', Proceedings of the 6th International Symposium on Landslides, A.A. Balkema, Rotterdam, pp. 1317-1321. 